\title{
Differential DNA Methylation of the IMMP2L Gene in Families with Maternally Inherited 7q31.1 Microdeletions is Associated with Intellectual Disability and Developmental Delay
}

\author{
Stanislav A. Vasilyev ${ }^{a}$ Nikolay A. Skryabin ${ }^{a} \quad$ Anna A. Kashevarova ${ }^{a} \quad$ Ekaterina N. Tolmacheva ${ }^{a}$ \\ Renata R. Savchenko ${ }^{a}$ Oksana Yu. Vasilyeva ${ }^{a}$ Maria E. Lopatkina ${ }^{a}$ Alexei A. Zarubin ${ }^{a}$

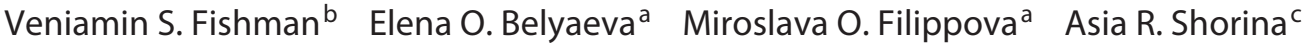 \\ Arkadiy B. Maslennikov ${ }^{c}$ Olga L. Shestovskikh ${ }^{d}$ Tatyana A. Gaynere,f Vida Culićg \\ Robert Vulićg Lyudmila P. Nazarenko ${ }^{a} \quad$ Igor N. Lebedev ${ }^{a}$ \\ aResearch Institute of Medical Genetics, Tomsk National Research Medical Center, Tomsk, Russia; b Institute of \\ Cytology and Genetics, SB RAS, Novosibirsk, Russia; 'Novosibirsk City Clinical Hospital, Novosibirsk, Russia; \\ dCity Perinatal Clinical Center, Omsk, Russia; "Group of Companies "Center of New Medical Technologies," \\ Novosibirsk, Russia; Institute of Chemical Biology and Fundamental Medicine, SB RAS, Novosibirsk, Russia; \\ ${ }^{9}$ Gynecology and Obstetrics Private Outpatient Clinic, Split, Croatia
}

\section{Keywords}

IMMP2L · Deletion · Copy number variation · DNA

methylation $\cdot$ Incomplete penetrance

\begin{abstract}
Most copy number variations (CNVs) in the human genome display incomplete penetrance with unknown underlying mechanisms. One such mechanism may be epigenetic modification, particularly DNA methylation. The IMMP2L gene is located in a critical region for autism susceptibility on chromosome 7q (AUTS1). The level of DNA methylation was assessed by bisulfite sequencing of 87 CpG sites in the IMMP2L gene in 3 families with maternally inherited 7q31.1 microdeletions affecting the $I M M P 2 L$ gene alone. Bisulfite sequencing revealed comparable levels of DNA methylation in the probands, healthy siblings without microdeletions, and their fathers. In contrast, a reduced DNA methylation index and increased IMMP2L expression were observed in lymphocytes from the healthy mothers compared with the probands. A number of genes were upregulated in the healthy mothers compared to controls and downregulated in probands com-
\end{abstract}

karger@karger.com

(c) 2021 S. Karger AG, Basel

www.karger.com/cgr

Karger $\stackrel{2}{=}$ pared to mothers. These genes were enriched in components of the ribosome and electron transport chain, as well as oxidative phosphorylation and various degenerative conditions. Differential expression in probands and mothers with IMMP2L deletions relative to controls may be due to compensatory processes in healthy mothers with IMMP2L deletions and disturbances of these processes in probands with intellectual disability. The results suggest a possible partial compensation for IMMP2L gene haploinsufficiency in healthy mothers with the 7q31.1 microdeletion by reducing the DNA methylation level. Differential DNA methylation of intragenic CpG sites may affect the phenotypic manifestation of CNVs and explain the incomplete penetrance of chromosomal microdeletions.

(c) 2021 S. Karger AG, Basel

\section{Introduction}

In the human genome, a wide spectrum of copy number variations (CNVs), most of which are phenotypically neutral, has been detected [MacDonald et al., 2014]. Nevertheless, the role of CNVs in the pathogenesis of com- 
mon and chromosomal diseases is important [Iyer and Girirajan, 2015; Christensen et al., 2016]. In the analysis of CNV-associated diseases, the identification of pathogenic CNVs among the widespread polymorphic variants and the risk of disease manifestation in other children in the family remain major issues. The mechanisms underlying the phenotypic manifestation of CNVs and their incomplete penetrance remain largely unclear. Most pathogenic CNVs in the human genome exhibit incomplete penetrance with unknown underlying mechanisms [Rosenfeld et al., 2013; Kirov et al., 2014].

Recently, de novo differentially methylated regions were shown to be significantly enriched in individuals with neurodevelopmental disorders and congenital anomalies [Barbosa et al., 2018]. These differentially methylated regions inside CNVs may be one of the mechanisms underlying the incomplete penetrance of inherited CNVs associated with neurodevelopmental disorders.

The IMMP2L gene is located in a critical region for autism susceptibility (AUTS1) on chromosome 7q. Mutations or intragenic CNVs in the IMMP2L gene are described in patients with Tourette syndrome (OMIM 137580), a neurological disorder characterized by motor and vocal tics, which is often accompanied by attention deficit disorder with hyperactivity (ADHD) and autism spectrum disorders (ASDs) [Elia et al., 2010]. Microdeletions of the first exons of this gene, which are 150-370 kb in size, were found in patients with epilepsy and speech and movement disorders [Gimelli et al., 2014]. Knockdown of the IMMP2L gene is known to lead to disruption of the expression of other genes involved in regulating the development of the central nervous system, which may determine the clinical manifestations [Gokoolparsadh et al., 2017]. Furthermore, a large-scale association study did not show a reliable association of IMMP2L deletions with ASD; in the Chinese population, the frequency of deletions among patients with ASD was approximately 2 times higher than in the control group (3 vs. 1.52\%) [Zhang et al., 2018].

Here, we report for the first time the differential DNA methylation of intragenic CpG sites of the IMMP2L gene in families with maternally inherited $7 \mathrm{q} 31.1$ microdeletions affecting the IMMP2L gene only.

\section{Materials and Methods}

\section{Families and Control Groups}

Family 1

Proband 1.1, a 3-year-old boy, was born in the 36th week of gestation by caesarean section. The child is from a twin pregnancy conceived after assisted reproductive technologies. His birth weight was $2,008 \mathrm{~g}$ ( $<2$ nd centile), birth length was $48 \mathrm{~cm}$ (25th centile), head circumference was $32 \mathrm{~cm}$ (3rd-5th centile), and chest circumference was $25 \mathrm{~cm}$ ( $<3 \mathrm{rd}$ centile). His Apgar score was 5-7. Since birth, the proband has been unable to suck properly and was fed with a feeding tube. He was able to sit at the age of 2 years and 6 months and walk with support at the age of 2 years and 2 months. At the age of 3 years, the patient does not speak. His height is $89 \mathrm{~cm}$ (25th centile), his weight is $15 \mathrm{~kg}$ (75th centile), and his head circumference is $50 \mathrm{~cm}$ (50th centile). The presence of some distinctive phenotypic features was noted, including a dolichocephalic skull, wide face, plump cheeks, frontal bossing, grey eyes, an almond-shaped palpebral fissure, epicanthus, strabismus, horizontal eyebrows, small, low-set ears, small nose, short columella, narrow mouth, downturned corners of the mouth, thin lips, long philtrum, blonde hair, a low posterior hairline, a square body shape, small hands and feet, light dry skin, and bilateral cryptorchidism. The patient only pronounces sounds. He exhibits a slight cognitive impairment and hyperphagia. The signs of ASD were present until 1 year of age, and they were further compensated. A magnetic resonance image showed perinatal hypoxia-induced ischaemic lesions of the white matter in both hemispheres of the brain.

\section{Family 2}

The family includes 2 siblings. Patient 2.1, a 14-year-old boy, was born at the 41 st week of gestation. His birth weight was 3,550 g (50th centile), birth length was $52 \mathrm{~cm}$ (50th centile), and head circumference was $34 \mathrm{~cm}$ (10th-25th centile). The Apgar score was $8-9$. He began to sit at 6.5 months of age and walk at 12 months. At the age of 14 years, the boy's speech is phrasal and full of grammatical errors. His height is $149 \mathrm{~cm}$ (50th centile), his weight is 37 $\mathrm{kg}$ (25-50th centile), and his head circumference is $53 \mathrm{~cm}$ (50th centile). Phenotypic features include a brachycephalic skull, long face, grey eyes, an almond-shaped palpebral fissure, epicanthus, short philtrum, blonde hair, a rectangular shape of the body, pectus excavatum, light skin, and right-sided cryptorchidism. The patient presents mild mental retardation (IQ 67, F70). A magnetic resonance image showed infiltrative changes in the mastoid process of the temporal bone on the left and minimal changes on the right. Patient 2.2, a 4-year-old boy, was born at 39-40 weeks of gestation. His birth weight was $3,450 \mathrm{~g}$ (50th centile), birth length was $50 \mathrm{~cm}$ (50th centile), and head circumference was $33 \mathrm{~cm}$ (5th10th centile). The Apgar score was 8-9. He began to sit at 7 months of age and walk at 10 months. At 4 years of age, the boy still does not speak. His height is $90 \mathrm{~cm}$ (75th centile), his weight is $13.6 \mathrm{~kg}$ (75th centile), and his head circumference is $49 \mathrm{~cm}$ (50th centile). Phenotypic features include a brachycephalic skull, long face, grey eyes, an almond-shaped palpebral fissure, short philtrum, blonde hair, a rectangular shape of the body, left-sided varus clubfoot, and light skin. The patient presents mixed specific developmental disorders (F83).

\section{Family 3}

Proband 3.1, a 6-year-old boy, was born at 40-41 weeks of gestation. His birth weight was $3,510 \mathrm{~g}$ (50th centile), and head circumference was $35 \mathrm{~cm}$ (25th centile). The Apgar score was 8-9. He began to sit at 8 months of age and walk at 12 months. His first words were spoken at 1 year and 2 months. At 4 years and 4 months, his height was $121 \mathrm{~cm}$ (>97th centile), his weight was 20.3 $\mathrm{kg}$ (90th centile), and his head circumference was $53 \mathrm{~cm}$ (>50th 
centile). Phenotypic features include long eyelashes, synophrys, hypertrichosis, and uneven rows of teeth. He is restless and periodically aggressive. Contact with other children is difficult. Dysarthria and echolalia were diagnosed. The patient displays signs of ASD and ADHD.

\section{Family 4}

Proband 4.1 is a boy aged 7 years and 8 months. He was born at the 40th week of gestation. His birth weight was 3,750 g (50th75 th centile), and his birth length was $52 \mathrm{~cm}$ (75th centile). During the last examination, the patient's weight was $26 \mathrm{~kg}$ (50th centile), and his height was $130 \mathrm{~cm}$ (75th centile). Phenotypic abnormalities include brachycephaly, flat face, periorbital cyanosis, fair hair, and impaired posture. The boy presents psychomotor and speech developmental delays and impaired behaviour. He has 2 healthy older siblings who were not investigated.

\section{Family 5}

A 28-year-old woman, who had already given birth to a healthy boy, was referred to a geneticist during her second pregnancy. The foetus (5.1) exhibited hypoplasia of the nasal bone, umbilical cyst, and chorion previa at ultrasound examination at 13 weeks and 4 days of gestation. At 13 weeks and 6 days, a biochemical analysis revealed an increased level of beta-hCG $(121.1 \mathrm{ng} / \mathrm{mL})$. Due to the presence of these markers of chromosomal abnormalities, conventional cytogenetic analysis was performed on amniocytes, and a foetal blood sample for array-CGH was collected by cordocentesis.

\section{Family 6}

The family was referred to a geneticist due to primary infertility after trying to become pregnant for 5 years. Both spouses had normal karyotypes by conventional cytogenetics. The man is 47 years old. He has no health complaints except for infertility. The 43-year-old woman (6.1) had diabetes insipidus and panhypopituitarism after surgery for craniopharyngioma when she was 15 years old. Currently, she is on hormone therapy. The woman was also deficient in growth hormone, thyrotropin, adrenocorticotropin, and follicle-stimulating hormone. The woman has a 38-year-old brother (6.2) who has 3 healthy children. The woman's mother also had a stillborn male child. According to the woman, the baby swallowed amniotic water and the umbilical cord was wrapped around the neck, which caused his death. The woman's father died of alcohol-induced cirrhosis of the liver.

\section{Control Group}

The control group consisted of 20 healthy individuals, comprising 10 men ( $42.6 \pm 6.3$ years old) and 10 women $(44.8 \pm 4.0$ years old), with no signs of intellectual disability. The GSE97760 dataset from the GEO database of the 10 healthy female individuals obtained using the same microarrays was used as group for comparison to analyse differential expression of the IMMP2L gene.

\section{Array-CGH and $q P C R$}

Unbalanced chromosomal rearrangements were detected using a SurePrint G3 Human CGH Microarray $(8 \times 60 \mathrm{~K})$ (Agilent Technologies, Santa Clara, CA, USA). All identified CNVs were confirmed using quantitative PCR with self-designed primers (online suppl. Table 1; for all online suppl. material, see www.karger. com/doi/10.1159/000514491), and their parental origin was established. PCR was performed with BioMaster HS-qPCR SYBR Blue mix (BioLabMix, Novosibirsk, Russia) on an AriaMx Real-time PCR system (Agilent Technologies). The detected microdeletions were compared with data generated by the DECIPHER community [Firth et al., 2009].

\section{Targeted Bisulfite Next-Generation Sequencing}

The DNA methylation level in the intragenic $\mathrm{CpG}$ of the IMMP2L gene was measured using bisulfite amplicon massive parallel sequencing. $\mathrm{CpG}$ sites for analysis were selected as being differentially methylated in various cell lines in the ENCODE project [Caiafa and Zampieri, 2005].

Genomic DNA was isolated from whole blood treated with proteinase K (Sigma, USA) for $16 \mathrm{~h}$ at $37^{\circ} \mathrm{C}$ followed by DNA purification with a mixture of phenol and chloroform. Bisulfite conversion of DNA was performed using the EZ DNA methylation Direct Kit (Zymo Research, Irvine, CA, USA) according to the manufacturer's protocol. After bisulfite conversion of DNA, amplification of the 288-480-bp products was performed using PCR with self-designed primers (online suppl. Table 2). The primers were designed using MethPrimer [Li and Dahiya, 2002], and their specificity was assessed with the BiSearch tool [Tusnády et al., 2005]. PCR was performed with BioMaster HS-Taq PCR-Color $(2 \times)$ PCR mix (BioLabMix). The following PCR conditions were used: primary denaturation, $15 \mathrm{~min}$ at $95^{\circ} \mathrm{C} ; 45$ cycles of $20 \mathrm{~s}$ at $95^{\circ} \mathrm{C}, 20 \mathrm{~s}$ at $50^{\circ} \mathrm{C}$, and $20 \mathrm{~s}$ at $72^{\circ} \mathrm{C}$; and terminal elongation, $5 \mathrm{~min}$ at $72^{\circ} \mathrm{C}$.

Amplified DNA was isolated using Sephadex G50 (Sigma, USA) and pooled for library generation. Adapters and indexes were attached with the Nextera XT kit (Illumina, San Diego, CA, USA) according to the manufacturer's protocol. Sequencing was performed on a MiSeq sequencer using the MiSeq Reagent Nano Kit v2 (Illumina) according to the manufacturer's protocol.

For the analysis of the targeted bisulfite sequencing, the obtained reads were filtered in the Trimmomatic programme with the threshold Phred of 30. Next, the filtered reads were aligned to in silico bisulfite converted DNA in BWA-MEM. Then, we counted the number of aligned nucleotides at each position and calculated the proportion of methylated cytosines with SAMtools and $R$ using the formula Methyl $=\mathrm{C} /(\mathrm{C}+\mathrm{T})$. The distribution of data was analysed using the Kolmogorov-Smirnov test.

All exons of the IMMP2L gene in families 1-3 were analysed for pathogenic single nucleotide variants with massive parallel sequencing after PCR using primers given in online supplementary Table 3.

\section{Gene Expression Microarrays}

RNA was isolated from whole blood using the guanidinium thiocyanate-phenol-chloroform-based method with LIRA reagent (BioLabMix, Novosibirsk, Russia) and subsequently purified using an RNeasy kit (Qiagen, Hilden, Germany) according to the manufacturer's protocol. RNA quality was assessed by measuring the RNA integrity number using a Bioanalyzer 2100 (Agilent Technologies) (RIN $=8-9)$. Labelling and hybridization were performed using SurePrint G3 Human GE v2, $8 \times 60 \mathrm{~K}$ microarrays (Agilent Technologies) with subsequent scanning using Agilent SureScan (Agilent Technologies) according to recommendations of the manufacturer. The statistical analysis and bioinformatics data processing were performed in R. Raw data were normalized 


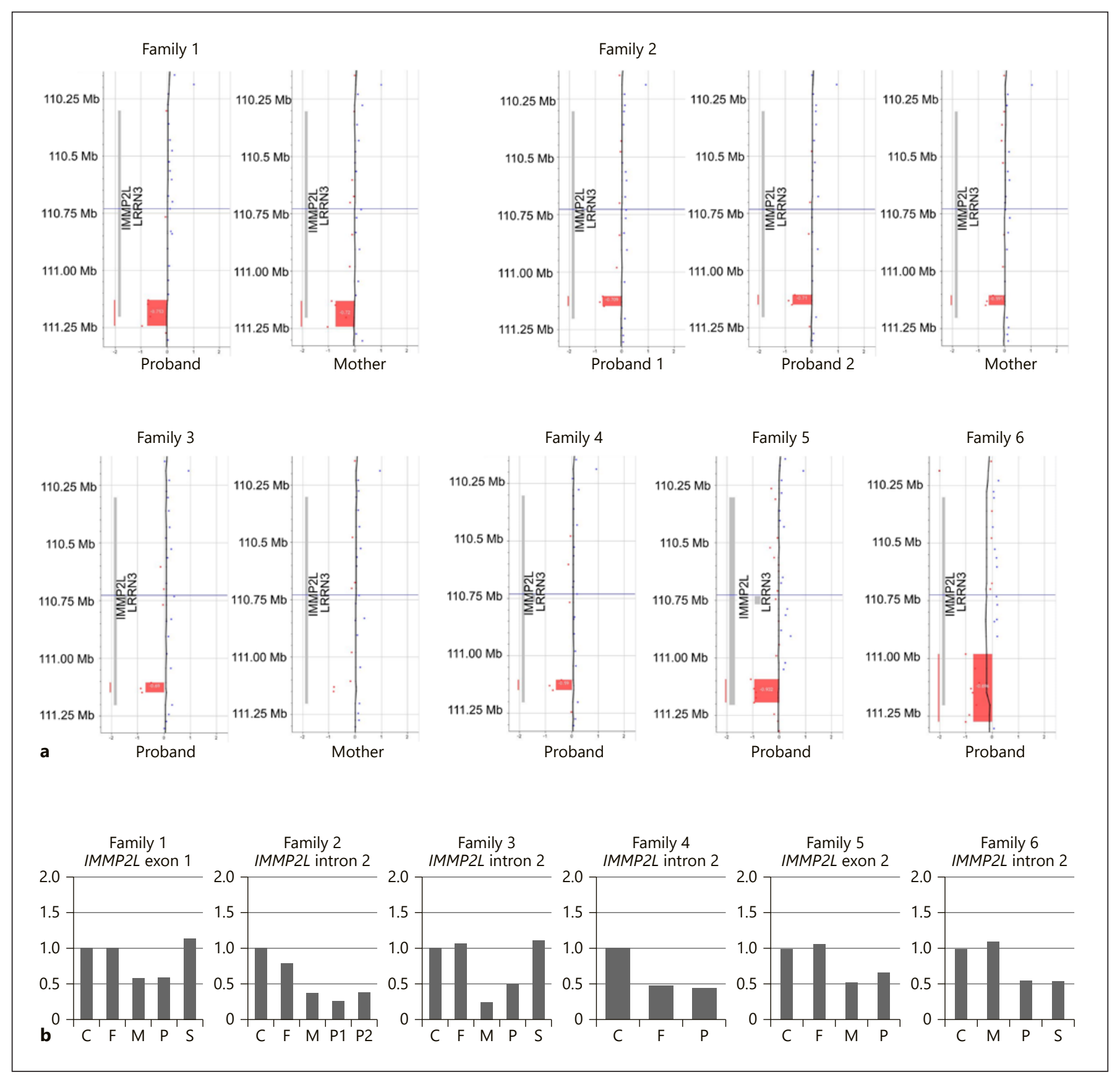

Fig. 1. Results of the microarray and $\mathrm{qPCR}$ analyses of the families with $I M M P 2 L$ gene deletions associated with intellectual disability. a IMMP2L gene deletions identified in the microarray analysis. Deletions are indicated by the red bars. b IMMP2L gene deletions identified in the qPCR analysis with primers for various regions of the IMMP2L gene. C, control; $\mathrm{F}$, father; $\mathrm{M}$, mother; $\mathrm{P}$, proband; $\mathrm{S}$, sibling.

and quantified using the limma library. The background was corrected, and loess normalization was performed. Data on gene expression in blood samples from the control group of women from the GEOSeries GSE38267 using the GEOquery package were used for the analysis. After data consolidation, quantile normalization was carried out.

\section{Results}

\section{Array-CGH and $q P C R$}

The aCGH assay using an Agilent 60K microarray revealed 7q31.1 deletions in all families (Fig. 1; Table 1). 
Table 1. Identified CNVs in the IMMP2L gene

\begin{tabular}{|c|c|c|c|c|c|}
\hline 1.1 & Male & 3 & $\begin{array}{l}\operatorname{arr}[\text { hg19] 7q31.1(110917835_111031367) } \times 1 \text { mat, } \\
15 \mathrm{q} 11.2 \mathrm{q} 13.1\left(23739358 \_28525460\right) \times 1 \mathrm{dn}\end{array}$ & 114 & $\begin{array}{l}\text { Promoter, } \\
\text { exons } 1-2\end{array}$ \\
\hline 2.1 & Male & 14 & $\operatorname{arr}[\mathrm{hg} 19]$ 7q31.1(111105151_111149166) $\times 1$ mat & 44 & Exon 3 \\
\hline 2.2 & Male & 4 & $\operatorname{arr}[$ hg19] 7q31.1(111105151_111149166)×1 mat & 44 & Exon 3 \\
\hline 3.1 & Male & 6 & $\operatorname{arr}[$ hg19] 7q31.1(111105151_111149166) $\times 1$ mat & 44 & Exon 3 \\
\hline 5.1 & Female & Foetus & $\operatorname{arr}[$ hg19] 1q25.1(175448847_175743250)×3, 7q31.1(111092431_111194656)×1 mat & 102 & Exon $2-3$ \\
\hline 6.1 & Female & 43 & $\operatorname{arr}\left[\right.$ hg19] 7q31.1(110980176_111274663) $\times 1^{\mathrm{a}}$ & 294 & Exon $1-3$ \\
\hline
\end{tabular}

${ }^{a}$ Unknown origin (but not maternal).

These microdeletions involved exons $1-3$ of the single IMMP2L gene.

\section{Family 1}

The aCGH analysis determined a 114-kb deletion of exons $1-2$ of the IMMP2L gene and a 4.9-Mb 15q11.2q13.1 deletion in the Prader-Willi/Angelman syndrome region (OMIM 167270/105830): arr[hg19] 7q31.1(110917835_ 111031367) ×1,15q11.2q13.1(23739358_28525460) $\times 1$. The clinical phenotype of the patient corresponds to Prader-Willi syndrome, which was confirmed by methylspecific PCR. The 7q31.1 deletion was verified by realtime PCR with primers for exon 1 of the IMMP2L gene. The deletion was maternal in origin. The second child from the twin pregnancy is healthy and, according to realtime PCR, does not have copy number changes in the IMMP2L gene.

\section{Family 2}

According to the aCGH analysis, both siblings carry identical $44-\mathrm{kb}$ deletions at 7q31.1, including exon 3 of the IMMP2L gene: $\operatorname{arr}[\mathrm{hg19}]$ 7q31.1(111105151_ $111149166) \times 1$. The breakpoints are localized in introns 2 and 3 . The deletions were confirmed by real-time PCR with primers for intron 2 of the IMMP2L gene and were shown to be inherited from the mother.

\section{Family 3}

The aCGH analysis showed a 44-kb deletion at 7q31.1, including exon 3 of the IMMP2L gene: $\operatorname{arr}[\mathrm{hg} 19]$ 7q31.1(111105151_111149166)×1. The breakpoints are localized in introns 2 and 3. The deletion was confirmed by real-time PCR with primers for intron 2 of the IMMP2L gene and was shown to be maternal in origin. IMMP2L deletion in the mother was not found to be statistically significant in the aCGH analysis, as only 3 probes of the microarray are located in the deleted region, but its presence was confirmed by qPCR. The older sibling of the proband is healthy and, according to real-time PCR, does not have IMMP2L gene copy number changes.

\section{Family 4}

The aCGH analysis showed a 44-kb deletion at 7q31.1, including exon 3 of the IMMP2L gene: $\operatorname{arr}[\mathrm{hg} 19] 7 \mathrm{q} 31.1$ (111105151_111149166) $\times 1$. The breakpoints are located in introns 2 and 3 . The deletion was confirmed by realtime PCR with primers for intron 2 of the IMMP2L gene and was shown to be paternal in origin.

\section{Family 5}

The mosaic 46,XX,+14,rob(14;14)(q10;q10)[8]/ 46,XX[18] karyotype was determined by amniocentesis. Cells with robertsonian translocation were detected in 1 flask only, indicating possible pseudomosaicism. We performed aCGH+SNP analysis using a DNA sample from cord blood to further exclude the possible segmental uniparental disomy for chromosome 14 and identified the arr[hg19] 1q25.1(175448847_175743250) $\times 3$, 7q31.1(111092431_111194656)×1 molecular karyotype. The 7q31.1 deletion affects exons 2 and 3 of the IMMP2L gene. Based on the results of real-time PCR with primers for exon 2 of the TNR gene (1q25.1) and exon 2 of the IMMP2L gene (7q31.1), both aberrations were maternal in origin. The family decided to terminate the pregnancy.

\section{Family 6}

The aCGH analysis identified a 294-kb deletion of exons $1-3$ of the IMMP2L gene in the index woman: arr[hg19] 7q31.1(110980176_111274663)×1. The deletion was confirmed by real-time PCR with primers for 


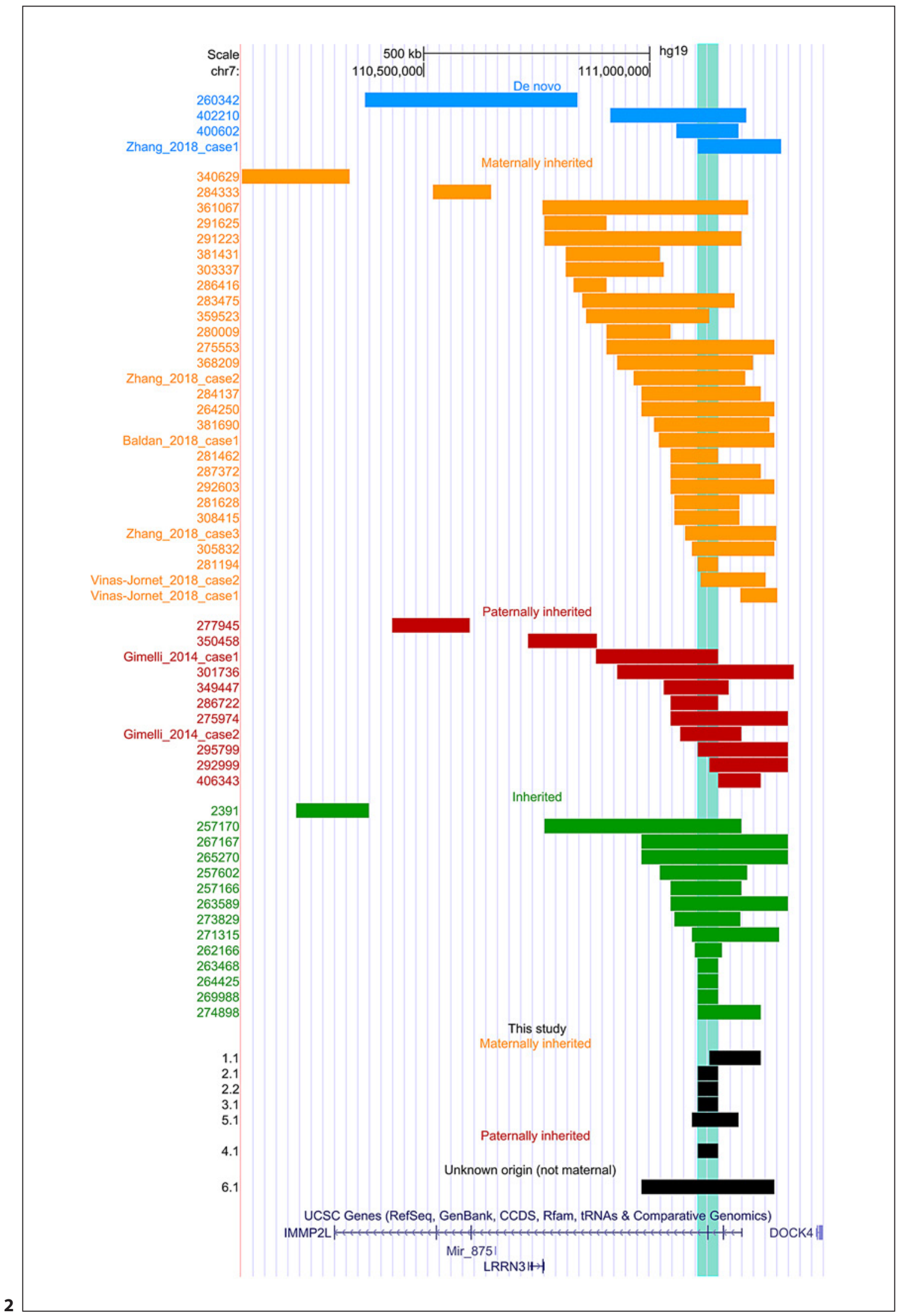

(For legend see next page.) 
exon 1 of the gene. The deletion was also found in her brother. Their mother did not exhibit any copy number changes in the IMMP2L gene, as based on real-time PCR. The father's DNA was not available for analysis. Realtime PCR and aCGH analyses did not reveal any copy number changes in the IMMP2L gene in the father's sister. The husband did not harbour any copy number changes in the IMMP2L gene according to real-time PCR and aCGH analysis. However, aCGH identified a $348-\mathrm{kb}$ duplication at $10 \mathrm{q} 11.23$ and a $557-\mathrm{kb}$ duplication at

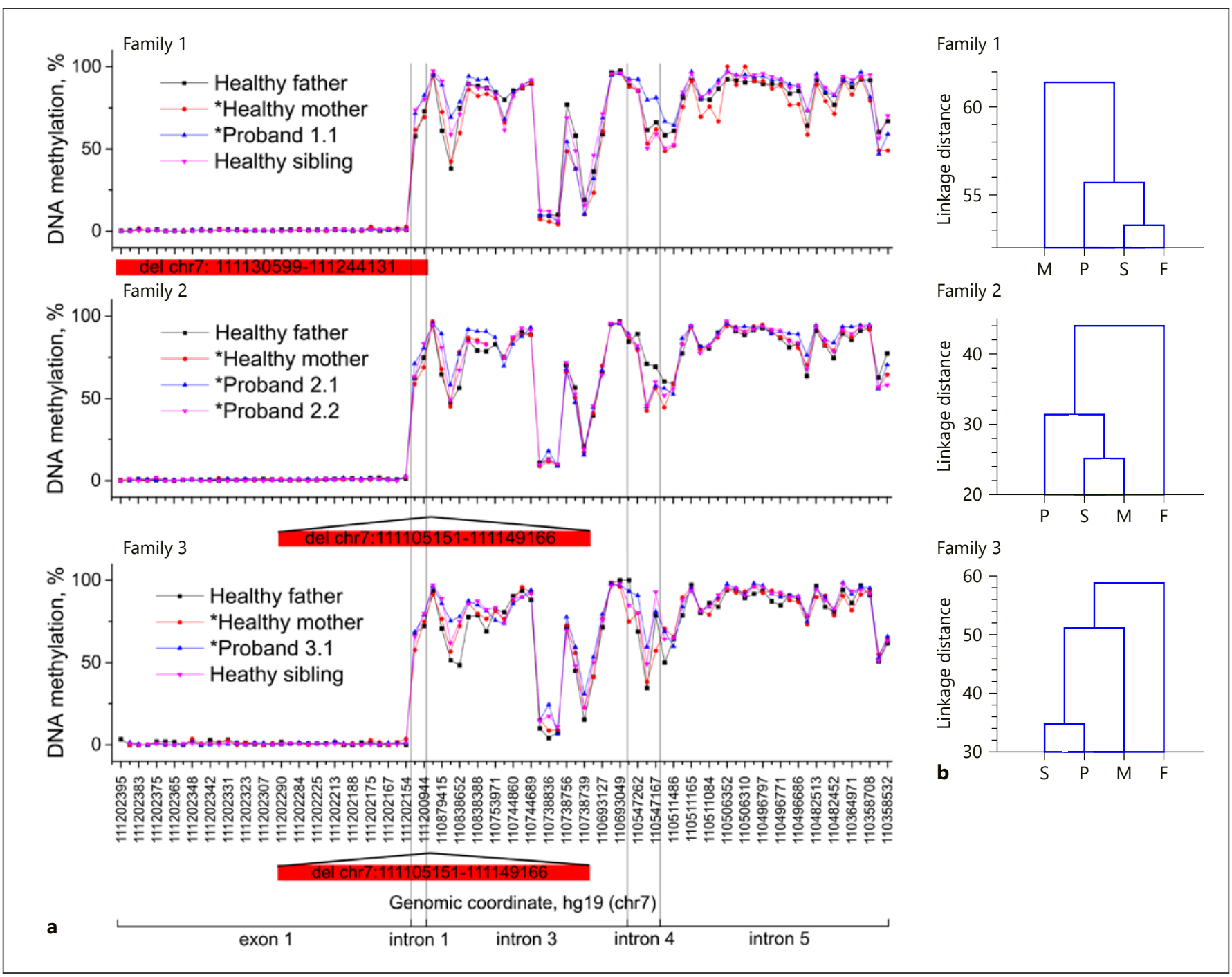

Fig. 3. DNA methylation at $\mathrm{CpG}$ sites in the IMMP2L gene in families with deletions in this gene. a DNA methylation profile. $\mathbf{b}$ Clustering analysis between family members. F, father; M, mother; $\mathrm{P}$, proband; S, sibling. * Denotes carriers of the IMMP2L gene dele- tion. Grey vertical lines mark the boundaries of exons and introns. In families 2 and 3 , the regions where the methylation analysis was performed did not coincide with the deletion region. For these regions, the deletion position is indicated using extension lines.
Fig. 2. Comparison of patients with a deletion of the IMMP2L gene analysed in this study with published cases and the DECIPHER database. Only deletions in the IMMP2L gene are shown. The link to the reference or DECIPHER ID is shown in the panel on the left. Patients with an IMMP2L deletion inherited from their father, mother, or one of their parents (if a particular parent is not specified in the DECIPHER database) are shown separately. The minimal overlapping critical region is indicated by the cyan-shaded area. The figure was created using the DECIPHER database [Firth et al., 2009] and the UCSC genome browser [Raney et al., 2014]. 
Table 2. Number of differentially methylated CpG sites in offspring in the families with deletions of the IMMP2L gene with respect to the level of parental DNA methylation (difference of more than $10 \%)$

\begin{tabular}{|c|c|c|c|c|}
\hline Family & Child & Control & $\begin{array}{l}\text { Hypermethylated } \\
\text { CpG sites } \\
(d>10 \%) \\
\text { in child, } n\end{array}$ & $\begin{array}{l}\text { Hypomethylated } \\
\text { CpG sites } \\
(d>10 \%) \\
\text { in child, } n\end{array}$ \\
\hline \multirow[t]{4}{*}{ Family 1} & \multirow[t]{2}{*}{ Proband 1.1} & Father & 6 & 5 \\
\hline & & Mother & 15 & 0 \\
\hline & \multirow{2}{*}{$\begin{array}{l}\text { Healthy } \\
\text { sibling }\end{array}$} & Father & 4 & 2 \\
\hline & & Mother & 17 & 0 \\
\hline \multirow[t]{4}{*}{ Family 2} & \multirow[t]{2}{*}{ Proband 2.1} & Father & 6 & 2 \\
\hline & & Mother & 5 & 0 \\
\hline & \multirow[t]{2}{*}{ Proband 2.2} & Father & 2 & 2 \\
\hline & & Mother & 2 & 1 \\
\hline \multirow[t]{4}{*}{ Family 3} & \multirow[t]{2}{*}{ Proband 3.1} & Father & 11 & 0 \\
\hline & & Mother & 8 & 0 \\
\hline & \multirow{2}{*}{$\begin{array}{l}\text { Healthy } \\
\text { sibling }\end{array}$} & Father & 9 & 1 \\
\hline & & Mother & 4 & 0 \\
\hline
\end{tabular}

15q25.2q25.3: $\operatorname{arr}[\mathrm{hg} 19]$ 10q11.23(51804961_52153320) $\times 3,15 q 25.2 q 25.3\left(85124542 \_85682231\right) \times 3$. The clinical significance of the duplications is currently unknown.

The microdeletions were confirmed using quantitative real-time PCR analysis and were shown to be inherited from apparently healthy mothers in 4 families, inherited from the father in 1 family, and probably de novo or inherited from the father in Family 6 (Fig. 1). Pathogenic effects of a deletion in the IMMP2L gene in probands potentially result from the mutation of the second allele. However, no pathogenic single nucleotide variants were identified in exons of the IMMP2L gene in the analysed families.

Deletions of the IMMP2L gene in our patients were compared with those in published cases [Gimelli et al., 2014; Baldan et al., 2018; Viñas-Jornet et al., 2018; Zhang et al., 2018] and the DECIPHER database (Fig. 2). Similar to the present study, most of the published deletions were inherited from apparently healthy parents. In these patients, a predominance of deletions of maternal origin was observed (Fig. 2). The vast majority of deletions included one or more of the first 3 exons of the IMMP2L gene, indicating a possible hot spot for the occurrence of
CNVs and delineating a minimal overlapping critical region (chr7:111105151_111149166, hg19). Frequent inheritance of IMMP2L gene deletions by patients from healthy parents indicates the incomplete penetrance of these CNVs. This incomplete penetrance may be due to the influence of alleles of other genes [Beckmann et al., 2007; Lee and Scherer, 2010] or changes in the epigenetic regulation of gene expression. Therefore, we analysed the level of DNA methylation in the promoter and gene body of the IMMP2L gene in patients with IMMP2L gene deletions and their parents.

\section{Differential DNA Methylation in Families}

DNA methylation was analysed in 3 families with maternally inherited 7q31.1 microdeletions (families 1-3). In all studied families, the DNA methylation profiles in the IMMP2L gene were similar: hypomethylation in exon 1 and a similar profile in all the studied introns (Fig. 3). Clustering analysis showed no preferential clustering between family members, which indicates the absence of a similar pattern of differences in the DNA methylation profile among the families. When comparing individual CpG sites between family members, a variation in the methylation level $>10 \%$ was observed only for individual CpG sites. Differentially methylated CpG sites displayed higher methylation levels in children than in both parents (Table 2). However, the level of these differences between children and parents was not the same for fathers and mothers with $I M M P 2 L$ deletion: in 2 families, more hypermethylated $\mathrm{CpG}$ sites (relative to both children) were observed in the mothers than in the fathers, and in another family, more sites were observed in the father than in the mother (Table 2). Differentially methylated CpG sites were generallylocated in various parts of the $I M M P 2 L$ gene in the analysed families. However, some differentially methylated $\mathrm{CpG}$ sites were common in all 3 families: intron 1 (site 111,201,083), intron 3 (sites 110,838,652; $110,879,264$; and 110,879,415), and intron 4 (site $110,547,167)$. All common differentially methylated CpG sites were more highly methylated in the children than in the parents.

\section{Differential DNA Methylation Compared with the Control Group}

We determined the methylation profile of individual CpG sites in the IMMP2L gene (differentially methylated CpG sites in individual families and $\mathrm{CpG}$ sites in close vicinity to them) in the control group of 20 healthy individuals to assess the extent to which the detected differentially methylated $\mathrm{CpG}$ sites correspond to the normal 
Fig. 4. The methylation profile of the analysed CpG sites in the IMMP2L gene in carriers of the IMMP2L gene deletion with intellectual disability compared to healthy carrier mothers and healthy individuals. The red line depicts the methylation profile of the probands, and the blue line corresponds to the methylation profile of the healthy mothers (carriers of deletions in the IMMP2L gene). The black squares depict the median level of DNA methylation at $\mathrm{CpG}$ sites in the control group; the blue area highlighted corresponds to the interquartile range, and the light blue area corresponds to outlier thresholds in the control group. Grey vertical lines mark the boundaries of exons and introns. In all families, the regions where the methylation analysis was performed did not completely coincide with the deletion region. For these regions, the deletion position is indicated using extension lines.

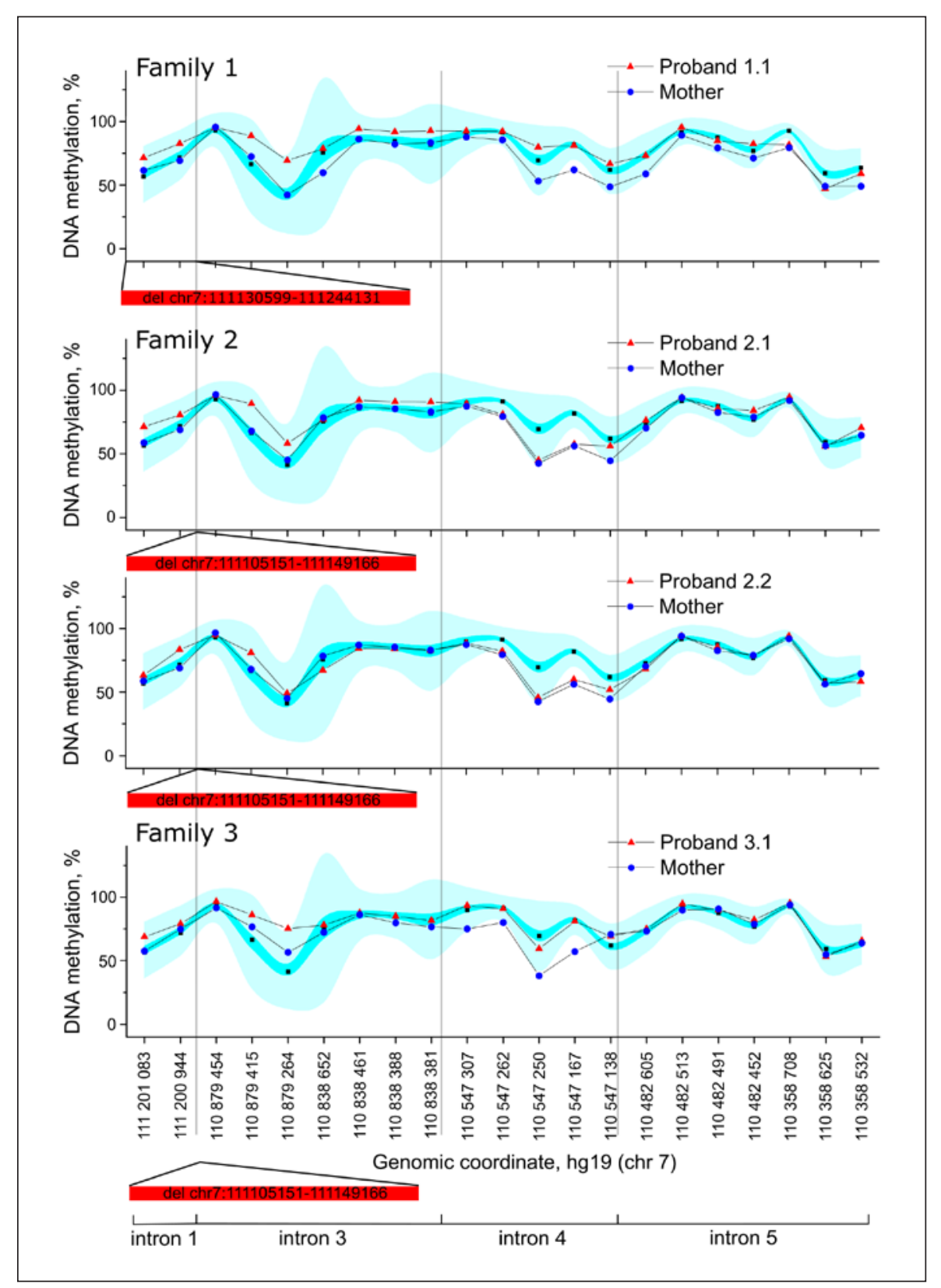

interindividual variability. The level of DNA methylation was greater than the variability in the control group (more than $3 \times$ the interquartile range from the 1 st and 3 rd quartile) for $18 \mathrm{CpG}$ sites in all individuals in all families (17 hypomethylated [7 different CpG sites] and 1 hypermethylated] (Fig. 4). In all families, the number of hypomethylated CpG sites was greater for the parents than for the children and for carrier mothers than for fathers compared with control group (Table 3). Thus, healthy mothers, who were carriers of IMMP2L gene deletions, had 2-3 hypomethylated CpG sites compared with the healthy individuals of comparable ages.

The majority of hypomethylated CpG sites were located in intron 4 ( 3 of 5) compared with the control group. One CpG site $(110,547,167$ - intron 4) was detected in 8 individuals and was hypomethylated in the healthy carrier mothers in all 3 families compared to the affected children. Three other sites $(110,547,262 ; 110,547,250$ intron 4, and 110,358,708 - intron 5) showed lower levels of methylation in 3 and 2 individuals, respectively, than 
Table 3. CpG sites with DNA hypomethylation in the families with deletion of the IMMP $2 L$ gene outside the lower outlier threshold in the control group

\begin{tabular}{|c|c|c|c|c|c|c|}
\hline \multirow[t]{2}{*}{ Family } & \multirow{2}{*}{$\begin{array}{l}\text { Family } \\
\text { member }\end{array}$} & \multicolumn{5}{|c|}{ Location of CpG (coordinate), chromosome 7, hg19 } \\
\hline & & $\begin{array}{l}\text { intron } 4 \\
(110547262)\end{array}$ & $\begin{array}{l}\text { intron } 4 \\
(110547250)\end{array}$ & $\begin{array}{l}\text { intron } 4 \\
(110547167)\end{array}$ & $\begin{array}{l}\text { intron } 5 \\
(110482513)\end{array}$ & $\begin{array}{l}\text { intron } 5 \\
(110358708)\end{array}$ \\
\hline \multirow[t]{4}{*}{1} & $\mathrm{~F}$ & 5.07 & 19.98 & -3.66 & 10.99 & 6.11 \\
\hline & $\mathrm{M}$ & 5.15 & 11.75 & -7.77 & 8.27 & -6.22 \\
\hline & P1.1 & 11.90 & 38.25 & 11.35 & 14.68 & -4.14 \\
\hline & $S$ & 5.21 & 8.87 & -10.58 & 13.49 & 9.55 \\
\hline \multirow[t]{4}{*}{2} & $\mathrm{~F}$ & 8.85 & 29.41 & -0.47 & 10.38 & 6.91 \\
\hline & $\mathrm{M}$ & -1.08 & 1 & -13.46 & 13.27 & 6.14 \\
\hline & P2.1 & 0.58 & 3.35 & -12.06 & 13.48 & 9.01 \\
\hline & P2.2 & 1.63 & 4.05 & -9.69 & 13.31 & 8.50 \\
\hline \multirow[t]{4}{*}{3} & $\mathrm{~F}$ & -11.66 & -6.92 & 8.84 & 15.83 & 5.31 \\
\hline & M & -0.41 & -3.36 & -12.59 & 8.98 & 8.23 \\
\hline & P3.1 & 10.26 & 17.91 & 11.25 & 13.95 & 9.67 \\
\hline & $\mathrm{S}$ & 0.14 & 7.60 & 23.13 & 13.85 & 6.25 \\
\hline
\end{tabular}

The lower outlier threshold was calculated by the formula $L O T=Q_{1}-I Q R \times 3$, where LOT is the lower outlier threshold, $Q_{1}$ is the 1st quartile, and IQR is the interquartile range. Numbers in the table were calculated by subtracting LOT from the DNA methylation index of each CpG site (\%). CpG sites with DNA hypomethylation in families with deletion of the IMMP2L gene outside the lower outlier threshold in the control group are indicated in bold.

in the control group (Table 3). Notably, 3 of these recurrent differentially methylated CpG sites $(110,547,167$; $110,547,262$; and $110,547,250)$ were located in endogenous retrovirus (ERV1) sequences.

\section{IMMP2L Gene Expression}

We assessed the expression of the IMMP2L gene in 2 families with inherited deletions using microarrays to analyse the effect of differential methylation at $\mathrm{CpG}$ sites in the IMMP2L gene on the expression of this gene. The GEOSeries GSE38267 dataset from the GEO database of healthy individuals obtained using the same microarrays was used as the group for comparison. The expression of the IMMP2L gene in lymphocytes of both the probands and the mothers was significantly lower than in the healthy controls (8.6- and 6.5-fold, respectively) (Fig. 5a). This finding indicates the effect of IMMP2L deletion on its expression level. In individual families, the expression of the IMMP2L gene was downregulated 1.4-fold in the probands relative to their mothers, which may be an effect of the differential methylation level.

Moreover, the DOCK4 gene, which is located in the $7 \mathrm{q} 31.1$ region next to the IMMP2L gene, but is not affected by deletions and not associated with autism-like social deficits [Guo et al., 2019], was downregulated in the probands and their mothers with IMMP2L deletions compared to the controls (2.7- and 2.0-fold, respectively). Based on these results, the deletion and/or differential methylation level of the IMMP2L gene affects the expression of a nearby gene, possibly due to changes in the CTCF-factor binding site located in introns 1 and 4 of $I M M P 2 L$ and modifications in the local chromatin conformation in this region.

The proband in Family 1 (1.1) displayed major differences in the gene expression profile as a result of the 15q11.2q13.1 deletion; therefore, he was excluded from further analyses of gene expression profiles. In addition to IMMP2L, both probands in Family 2 and mothers in Families 1 and 2 presented multiple differentially expressed genes (both up- and downregulated) compared to the controls (Fig. 5b). Downregulated genes in both the probands and the mothers were not enriched in functional pathways. In contrast, genes upregulated in both the probands and the mothers with IMMP2L deletions were enriched in various KEGG pathways, including ribosome, spliceosome, proteasome, lysosome regulation, apoptosis, and autophagy (Fig. 5c). However, 8 of 10 downregulated genes in the probands with intellectual disability with maternal IMMP2L gene deletions compared to their mothers and the healthy controls were as- 

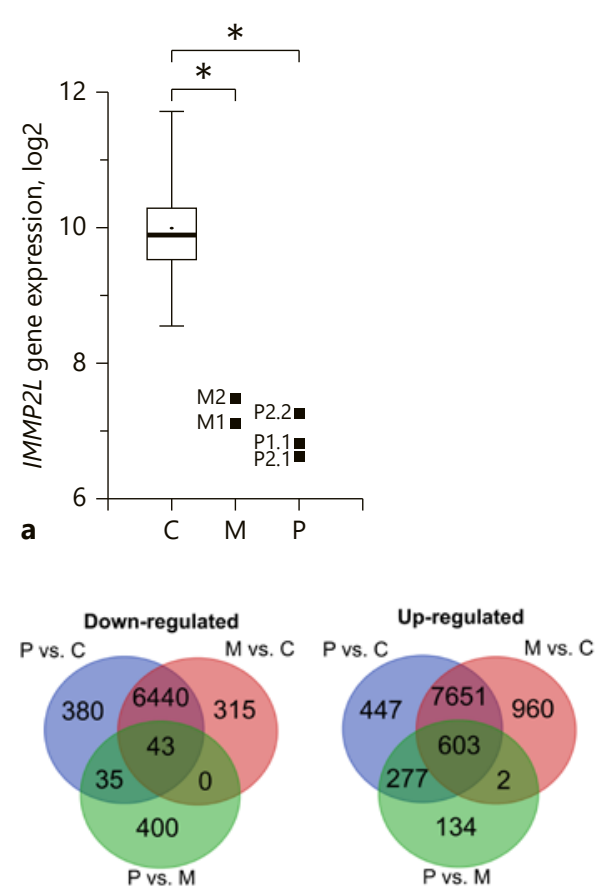

Up-regulated in mothers and down-regulated in probands M vs. C Up Pvs. M Down

\section{b}

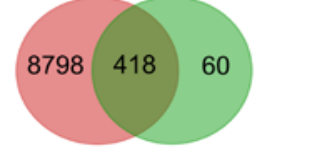

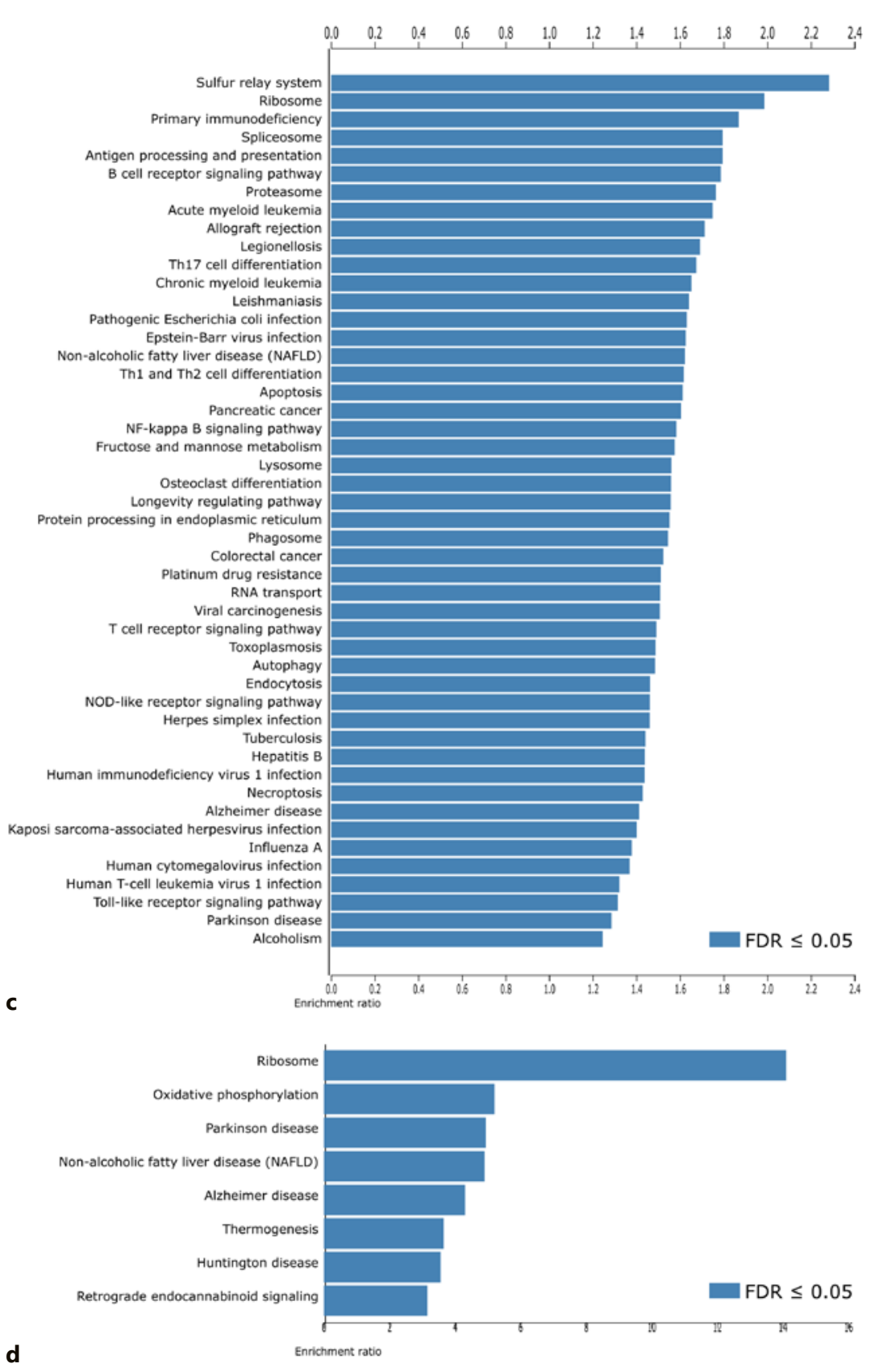

(P vs. $\mathrm{M}$ ) and the healthy controls (P vs. C) and in the mothers compared to the healthy controls ( $\mathrm{M}$ vs. C). c Enriched KEGG pathways among the differentially expressed genes that were upregulated in both the probands and the mothers compared to the healthy controls. d Enriched KEGG pathways among the differentially expressed genes that were upregulated in the mothers compared to the healthy controls, but downregulated in the probands compared to the mothers. 
Table 4. Top 10 downregulated genes in the probands with intellectual disability with maternal IMMP2L gene deletions compared to their mothers and the controls

\begin{tabular}{lllll}
\hline \multirow{2}{*}{ Gene } & \multicolumn{2}{l}{$\log _{2}$ fold change of gene expression level, FDR < 0.05 } & & Relationship with ASD and intellectual disability \\
\cline { 2 - 3 } & $\begin{array}{l}\text { Probands versus } \\
\text { control }\end{array}$ & $\begin{array}{l}\text { Mothers versus } \\
\text { control }\end{array}$ & $\begin{array}{l}\text { Probands versus } \\
\text { mothers }\end{array}$ & \\
\hline UQCRB & -1.08 & 1.80 & -2.88 & Exp_down [Kuwano et al., 2011] \\
COX7B & -1.06 & 1.42 & -2.48 & Exp_down [Anitha et al., 2012; Ginsberg et al., 2012] \\
CKLF & -4.46 & -2.55 & -1.92 & Exp_down [Ghahramani Seno et al., 2011] \\
RALGDS & -1.81 & & & CNV [Pinto et al., 2010b] \\
CLEC7A & -3.13 & -1.49 & -1.85 & Exp_up [Voineagu et al., 2011] \\
GOLGA6C & -1.36 & 0.17 & -1.64 & Linkage [Bennabi et al., 2015] \\
MALAT1 & -2.27 & -0.76 & -1.53 & ND \\
CNTNAP3 & -1.59 & -0.26 & -1.51 & CNV [Nord et al., 2011] \\
SFN & -2.03 & -0.71 & -1.32 & NDV [Gregory et al., 2009; Pinto et al., 2010a] \\
OTUD6B-AS1 & -2.39 & -1.13 & -1.26 & OMIM 617452 [Santiago-Sim et al., 2017] \\
\hline
\end{tabular}

sociated with ASD and intellectual disability (Table 4). Moreover, the 2 top downregulated genes in the probands compared to their mothers (UQCRB and $C O X 7 B$ ) were upregulated in the mothers compared to the healthy controls. Finally, all genes that were upregulated in the mothers compared to the controls and downregulated in the probands compared to the mothers were enriched in components of the ribosome and the electron transport chain (Fig. 5d; online suppl. Tables 4 and 5). As gene enrichment in oxidative phosphorylation was observed, genes associated with various degenerative conditions were also enriched. Differential expression in probands and mothers with $I M M P 2 L$ deletions compared to the controls is suggested to be a consequence of compensatory processes occurring in the healthy mothers with $I M M P 2 L$ deletions and the disruption of these processes in the probands with intellectual disability.

\section{Discussion}

In this study, we observed differential DNA methylation in the IMMP2L gene in families with inherited maternal deletions in this gene. At particular intragenic $\mathrm{CpG}$ sites, the level of DNA methylation is lower in the lymphocytes of heathy mothers (carriers of the IMMP2L gene deletion) than in other members of the families and healthy individuals. All these CpG sites are located in the IMMP2L gene body (particularly in intron 4) but not in the $\mathrm{CpG}$ islands in the promoter. Moreover, the expression of the IMMP2L gene in the lymphocytes of the healthy mothers is comparable to the control group, despite deletions in the IMMP2L gene, and is depleted in affected children with the same deletions. This result indicates the existence of compensatory factors in maternal cells, and differential methylation at $\mathrm{CpG}$ sites in the $I M M P 2 L$ gene may be one of these factors. However, the pathogenic significance of the differentially methylated CpG sites we identified remains unclear.

The possible role of DNA methylation in inherited deletions in humans was suggested in an analysis of specific language disorder in siblings with and without deletion of the ZNF277 gene at the AUTS1 locus [Ceroni et al., 2014; Pembrey et al., 2015; Skryabin et al., 2017], but a subsequent study did not confirm this hypothesis [Ceroni et al., 2015]. Similar results were observed in siblings with ASD with and without a deletion in the OXTR gene [Gregory et al., 2009]. Recently, differentially methylated regions were identified in close vicinity of adjacent inherited CNVs in individuals with neurodevelopmental disorders and congenital anomalies [Barbosa et al., 2018].

The IMMP2L gene encodes a protein of the mitochondrial inner membrane and is a candidate gene for Tourette syndrome [Bertelsen et al., 2014]. The gene is expressed in the brain, heart, kidneys, and some other tissues, but not in the lungs and liver of adults [Petek et al., 2007; Bertelsen et al., 2014]. Intron 3 of IMMP2L contains the neuronal gene LRRN3 [Maestrini et al., 2010]. $I M M P 2 L$ is thought to be associated with Alzheimer disease [Swaminathan et al., 2012], ADHD [Elia et al., 2010], schizophrenia [Goes et al., 2015], and other neurological disorders. In addition, this gene is located in the critical 
region of the ASD locus on chromosome $7 \mathrm{q}$ (AUTS1). However, when summarizing data from 5,568 patients with ASD and 10,279 healthy individuals, no association was observed between the microdeletion in the IMMP2L gene and autism [Zhang et al., 2018]. Nevertheless, at present, a pathogenic effect of mutations in the IMMP2L gene on the neuropsychiatric development of an individual cannot be excluded. In addition, female mice with a homozygous mutation of this gene are infertile due to defects in folliculogenesis and ovulation, and in mutant males, the level of apoptosis in the testes increases with age, which also significantly reduces their reproductive ability [Soler et al., 2010]. Therefore, as a mitochondrial protein, IMMP2L may also regulate processes in the reproductive system. This hypothesis was confirmed by the identification of IMMP2L gene deletions in patients with primary infertility in our study.

DNA methylation at $\mathrm{CpG}$ sites with intermediate methylation levels tends to exhibit high heritability and high interindividual variation [van Dongen et al., 2016]. These CpG sites are enriched in CpG island shores, intergenic regions, distal promoters, and downstream regions [van Dongen et al., 2016]. Potentially, differential methylation in the body of the IMMP2L gene may affect its expression and phenotypic manifestation. This hypothesis is also indicated by the reduced expression of the IMMP2L gene in probands with intellectual disability and increased IMMP2L methylation compared to their mothers.

IMMP2L is a protein that provides normal protein transport to the inner mitochondrial membrane, and its mutation leads to elevated mitochondrial superoxide levels, impaired fertility, and age-dependent neurodegeneration in mice [Liu et al., 2016]. Upregulation of the components of the electron transport chain observed in this study may be a compensatory mechanism for low expression of $I M M P 2 L$ in the mothers of probands with IMMP $2 L$ deletions, which resulted in masking of the pathological phenotype of IMMP2L deletions. However, for some reason, this compensation does not occur in probands with the same deletions. One explanation for these findings may be an increased level of methylation of individual CpG sites in the body of the IMMP2L gene and an even greater decrease in its expression compared to the healthy mothers. Because mitochondrial dysfunction is closely associated with neurodegenerative diseases, the mothers of probands with $I M M P 2 L$ deletions may be at risk for early-onset Alzheimer disease or Parkinson disease in the future.

Differential DNA methylation of intragenic CpG sites may affect the phenotypic manifestation of CNVs and explain the incomplete penetrance of unbalanced micro- structural chromosomal rearrangements. In particular, a decrease in DNA methylation at these regulatory sites may underlie the dose compensation of gene products in healthy CNV carriers. However, causal relationships between the level of methylation of intragenic CpG sites in the IMMP2L gene and its expression are unknown. In addition, the study was conducted on peripheral blood lymphocytes, whereas the main functions of IMMP2L, which is potentially associated with mental retardation, occur in the brain. DNA methylation and expression studies in neuronal cell cultures derived from induced pluripotent stem cells obtained from probands with IMMP2L deletion and healthy parents of deletion carriers will be needed to identify the effect of differential methylation on the function of IMMP2L in the brain.

Differential DNA methylation in patients with deletion of the IMMP2L gene was only observed in the families with a maternally inherited IMMP2L deletion. Therefore, the results suggest the need for a more detailed analysis of CNVs inherited from phenotypically healthy parents. A review of the potential pathogenic significance of structural chromosomal abnormalities occurring in healthy individuals is needed. In the practice of genetic counselling, the introduction of additional analyses of the epigenetic status will also require a diagnosis of chromosomal disorders.

\section{Acknowledgements}

This study used data generated by the DECIPHER community. A full list of centres that contributed to the generation of the data is available from https://decipher.sanger.ac.uk and via email from decipher@sanger.ac.uk. Funding for the project was provided by the Wellcome Trust. Investigators who performed the original analyses and collected the data bear no responsibility for the further analysis or interpretation by the recipient or its registered users. The molecular cytogenetic and molecular genetic studies were performed at the Core Facility "Medical Genomics" of the Tomsk National Research Medical Centre of the Russian Academy of Sciences using the resources of the biocollection "Biobank of the Population of Northern Eurasia" of the Research Institute of Medical Genetics, Tomsk NRMC. We would like to thank all families for their assistance with the clinical evaluation.

\section{Statement of Ethics}

Research was conducted ethically in accordance with the World Medical Association Declaration of Helsinki. Subjects (or their parents or guardians) have provided written informed consent. Approval was granted by the local Research Ethics Committee of the Research Institute of Medical Genetics, Tomsk NRMC (Date July 27, 2017/No. 106).
Differential DNA Methylation of the IMMP2L Gene in Microdeletion Regions
Cytogenet Genome Res 2021;161:105-119 DOI: $10.1159 / 000514491$ 


\section{Conflict of Interest Statement}

The authors have no conflicts of interest to declare.

\section{Funding Sources}

This study was supported by the Russian Science Foundation (project 16-15-10229) and by the state contract between the Ministry of Science and Higher Education of Russian Federation and Research Institute of Medical Genetics, Tomsk National Research Medical Centre, Russian Academy of Sciences, Tomsk (registration no. AAAA-A19-119020890005-5). The sponsors had no role in the design, methods, subject recruitment, data collection, analysis, or preparation of the manuscript.

\section{Author Contributions}

Conceptualization: S.A. Vasilyev, N.A. Skryabin, I.N. Lebedev. Methodology: S.A. Vasilyev, N.A. Skryabin. Formal analysis and investigation: S.A. Vasilyev, N.A. Skryabin, A.A. Kashevarova, E.N. Tolmacheva, R.R. Savchenko, O.Yu. Vasilyeva, M.E. Lopatkina, A.A. Zarubin, V.S. Fishman. Writing, original draft preparation: S.A. Vasilyev. Writing, review, and editing: S.A. Vasilyev, A.A. Kashevarova, N.A. Skryabin, I.N. Lebedev. Funding acquisition: N.A. Skryabin, I.N. Lebedev. Resources: E.O. Belyaeva, M.O. Filippova, A.R. Shorina, A.B. Maslennikov, O.L. Shestovskich, T.A. Gayner, V. Čulić, R. Vulić, L.P. Nazarenko. Supervision: I.N. Lebedev.

\section{References}

Anitha A, Nakamura K, Thanseem I, Yamada K, Iwayama $\mathrm{Y}$, Toyota $\mathrm{T}$, et al. Brain region-specific altered expression and association of mitochondria-related genes in autism. Mol Autism. 2012;3(1): 12 .

Baldan F, Gnan C, Franzoni A, Ferino L, Allegri $\mathrm{L}$, Passon N, et al. Genomic deletion involving the IMMP2L gene in two cases of autism spectrum disorder. Cytogenet Genome Res. 2018; 154(4):196-200.

Barbosa M, Joshi RS, Garg P, Martin-Trujillo A, Patel N, Jadhav B, et al. Identification of rare de novo epigenetic variations in congenital disorders. Nat Commun. 2018;9(1):2064

Beckmann JS, Estivill X, Antonarakis SE. Copy number variants and genetic traits: Closer to the resolution of phenotypic to genotypic variability. Nat Rev Genet. 2007;8(8):639-46.

Bennabi M, Delorme R, Oliveira J, Fortier C, Lajnef M, Boukouaci W, et al. Dectin-1 polymorphism: A genetic disease specifier in autism spectrum disorders?. PLoS One. 2015;10(9): e0137339.

Bertelsen B, Melchior L, Jensen LR, Groth C, Glenthøj B, Rizzo R, et al. Intragenic deletions affecting two alternative transcripts of the IMMP2L gene in patients with Tourette syndrome. Eur J Hum Genet. 2014;22(11):12839.

Caiafa P, Zampieri M. DNA methylation and chromatin structure: The puzzling $\mathrm{CpG}$ islands. J Cell Biochem. 2005;94(2):257-65.

Ceroni F, Simpson NH, Francks C, Baird G, Conti-Ramsden G, Clark A, et al. Homozygous microdeletion of exon 5 in ZNF277 in a girl with specific language impairment. Eur J Hum Genet. 2014;22(10):1165-71.

Ceroni F, Simpson NH, Francks C, Baird G, Conti-Ramsden G, Clark A, et al. Reply to Pembrey et al: 'ZNF277 microdeletions, specific language impairment and the meiotic mismatch methylation (3M) hypothesis'. Eur J Hum Genet. 2015;23:1113-5.

Christensen DL, Baio J, Van Naarden Braun K, Bilder D, Charles J, Constantino JN, et al.
Prevalence and characteristics of autism spectrum disorder among children aged 8 years-autism and developmental disabilities monitoring network, 11 sites, United States, 2012. MMWR Surveill Summ. 2016;65(3):1-23.

Elia J, Gai X, Xie HM, Perin JC, Geiger E, Glessner JT, et al. Rare structural variants found in attention-deficit hyperactivity disorder are preferentially associated with neurodevelopmental genes. Mol Psychiatry. 2010;15(6): 637-46.

Firth HV, Richards SM, Bevan AP, Clayton S, Corpas M, Rajan D, et al. Decipher: Database of Chromosomal Imbalance and Phenotype in Humans using Ensembl Resources. Am J Hum Genet. 2009;84(4):524-33.

Ghahramani Seno MM, Hu P, Gwadry FG, Pinto D, Marshall CR, Casallo G, et al. Gene and miRNA expression profiles in autism spectrum disorders. Brain Res. 2011;1380:85-97.

Gimelli S, Capra V, Di Rocco M, Leoni M, Mirabelli-Badenier M, Schiaffino MC, et al. Interstitial 7q31.1 copy number variations disrupting IMMP2L gene are associated with a wide spectrum of neurodevelopmental disorders. Mol Cytogenet. 2014;7:54.

Ginsberg MR, Rubin RA, Falcone T, Ting AH, Natowicz MR. Brain transcriptional and epigenetic associations with autism. PLoS One. 2012; 7:e44736.

Goes FS, McGrath J, Avramopoulos D, Wolyniec P, Pirooznia M, Ruczinski I, et al. Genomewide association study of schizophrenia in Ashkenazi Jews. Am J Med Genet B Neuropsychiatr Genet. 2015;168(8):649-59.

Gokoolparsadh A, Fang Z, Braidy N, Lin P, Pardy CJ, Eapen V, et al. Transcriptional response to mitochondrial protease IMMP2L knockdown in human primary astrocytes. Biochem Biophys Res Commun. 2017;482(4):1252-8.

Gregory SG, Connelly JJ, Towers AJ, Johnson J, Biscocho D, Markunas CA, et al. Genomic and epigenetic evidence for oxytocin receptor deficiency in autism. BMC Med. 2009;7:62.
Guo D, Peng Y, Wang L, Sun X, Wang X, Liang $\mathrm{C}$, et al. Autism-like social deficit generated by Dock 4 deficiency is rescued by restoration of Rac1 activity and NMDA receptor function. Mol Psychiatry. 2019.

ISCN 2016. An International System for Human Cytogenomic Nomenclature (2016). Cytogenet Genome Res. 2016;149(1-2):1-140.

Iyer J, Girirajan S. Gene discovery and functional assessment of rare copy-number variants in neurodevelopmental disorders. Brief Funct Genomics. 2015;14(5):315-28.

Kirov G, Rees E, Walters JT, Escott-Price V, Georgieva $\mathrm{L}$, Richards AL, et al. The penetrance of copy number variations for schizophrenia and developmental delay. Biol Psychiatry. 2014;75(5):378-85.

Kuwano Y, Kamio Y, Kawai T, Katsuura S, Inada N, Takaki A, et al. Autism-associated gene expression in peripheral leucocytes commonly observed between subjects with autism and healthy women having autistic children. PLoS One. 2011;6(9):e24723.

Lee C, Scherer SW. The clinical context of copy number variation in the human genome. Expert Rev Mol Med. 2010;12:e8.

Li LC, Dahiya R. MethPrimer: designing primers for methylation PCRs. Bioinformatics. 2002; 18(11):1427-31.

Liu C, Li X, Lu B. The Immp2l mutation causes age-dependent degeneration of cerebellar granule neurons prevented by antioxidant treatment. Aging Cell. 2016;15(1):167-76.

MacDonald JR, Ziman R, Yuen RK, Feuk L, Scherer SW. The database of genomic variants: A curated collection of structural variation in the human genome. Nucleic Acids Res. 2014;42(Database issue):D986-92.

Maestrini E, Pagnamenta AT, Lamb JA, Bacchelli E, Sykes NH, Sousa I, et al. High-density SNP association study and copy number variation analysis of the AUTS1 and AUTS5 loci implicate the IMMP2L-DOCK4 gene region in autism susceptibility. Mol Psychiatry. 2010; 15(9):954-68. 
Nord AS, Roeb W, Dickel DE, Walsh T, Kusenda $\mathrm{M}, \mathrm{O}$ 'Connor KL, et al. Reduced transcript expression of genes affected by inherited and de novo CNVs in autism. Eur J Hum Genet. 2011;19(6):727-31.

Pembrey M, Golding J, Connelly J. ZNF277 microdeletions, specific language impairment and the meiotic mismatch methylation (3M) hypothesis. Eur J Hum Genet. 2015;23(9): 1113.

Petek E, Schwarzbraun T, Noor A, Patel M, Nakabayashi K, Choufani S, et al. Molecular and genomic studies of IMMP2L and mutation screening in autism and Tourette syndrome. Mol Genet Genomics. 2007;277(1):71-81.

Pinto D, Pagnamenta AT, Klei L, Anney R, Merico D, Regan R, et al. Functional impact of global rare copy number variation in autism spectrum disorders. Nature. 2010a;466(7304): $368-72$.

Pinto MM, Santos NF, Amaral A. Current status of biodosimetry based on standard cytogenetic methods. Radiat Environ Biophys. 2010b; 49(4):567-81.
Raney BJ, Dreszer TR, Barber GP, Clawson H, Fujita PA, Wang T, et al. Track data hubs enable visualization of user-defined genome-wide annotations on the UCSC Genome Browser. Bioinformatics. 2014;30(7):1003-5.

Rosenfeld JA, Coe BP, Eichler EE, Cuckle H, Shaffer LG. Estimates of penetrance for recurrent pathogenic copy-number variations. Genet Med. 2013;15(6):478-81.

Santiago-Sim T, Burrage LC, Ebstein F, Tokita MJ, Miller M, Bi W, et al. Biallelic variants in OTUD6B cause an intellectual disability syndrome associated with seizures and dysmorphic features. Am J Hum Genet. 2017;100(4): 676-88.

Skryabin NA, Vasilyev SA, Lebedev IN. Epigenetic silencing of genomic structural variations. Russ J Genet. 2017;53(10):1072-9.

Soler R, Füllhase C, Lu B, Bishop CE, Andersson KE. Bladder dysfunction in a new mutant mouse model with increased superoxide-lack of nitric oxide?. J Urol. 2010;183(2): $780-5$.

Swaminathan S, Shen L, Kim S, Inlow M, West JD, Faber KM, et al. Analysis of copy number variation in Alzheimer's disease: The NIALOAD/NCRAD Family Study. Curr Alzheimer Res. 2012;9(7):801-14
Tusnády GE, Simon I, Varadi A, Aranyi T. BiSearch: Primer-design and search tool for PCR on bisulfite-treated genomes. Nucleic Acids Res. 2005;33(1):e9.

van Dongen J, Nivard MG, Willemsen G, Hottenga JJ, Helmer Q, Dolan CV, et al. Genetic and environmental influences interact with age and sex in shaping the human methylome. Nat Commun. 2016;7:11115.

Viñas-Jornet M, Esteba-Castillo S, Baena N, Ribas-Vidal N, Ruiz A, Torrents-Rodas D, et al. High incidence of copy number variants in adults with intellectual disability and co-morbid psychiatric disorders. Behav Genet. 2018; 48(4):323-36.

Voineagu I, Wang X, Johnston P, Lowe JK, Tian Y, Horvath S, et al. Transcriptomic analysis of autistic brain reveals convergent molecular pathology. Nature. 2011;474(7351):380-84.

Zhang Y, Liu Y, Zarrei M, Tong W, Dong R, Wang Y, et al. Association of IMMP2L deletions with autism spectrum disorder: A trio family study and meta-analysis. Am J Med Genet. 2018;177(1):93-100. 